ISSN: 2277-3754

ISO 9001:2008 Certified

International Journal of Engineering and Innovative Technology (IJEIT)

Volume 10, Issue 8, February 2021

\title{
A proposed LAAS with planer structure well array
}

\author{
Masato Shichijo, Keita Kosugi, Yuki Hasegawa, Hidekazu Uchida
}

Department of Electrical and Electronic Engineering, Saitama University, Japan

\begin{abstract}
We have studied the Light Addressable Amperometric Sensor (LAAS) which is a two dimensional electrochemical sensor. In this study we report the LAAS that enables multiples samples measurement based on planer structure made by photolithography. We deposited $S U-8$ and platinum films on the LAAS device to form well array in order to keep individual sample solutions. The LAAS performs individual measurements by selecting each well using addressing light beam. The results showed that the observed current value depends on concentration of redox species from 10pM to $1 \mathrm{mM}$ in 1 well. Therefore, we found that the proposed structure functions correctly, and expect efficiency improvement of processes such as drug discovery screening.
\end{abstract}

Keywords: Light Addressable Amperometric Sensor, LAAS, array sensor, drug screening, photolithography.

\section{BACKGROUND/ OBJECTIVES AND GOALS}

Demand of pharmaceutical products has been increasing in recent years due to lack of pharmaceuticals [1], so efficiency of drug development is an urgent problem. The commercialization process of drugs is as follows; drug discovery, drug development, regulatory, and marketing [2]. We can expect shortening of development time and cost reduction by streamlining screening which can be classified as drug discovery.

Fluorescence measurement is a method that is representative of powerful screening. It takes time to design fluorescent molecule in order to evaluate molecular functions although it makes possible to measure multiple samples simultaneously [3].

Manuscript received: 19 January 2021

Manuscript received in revised form: 14 February 2021

Manuscript accepted: 04 March 2021

Manuscript Available online: 15 March 2021
On the other hand, electrochemical sensors such as the light addressable potentiometric sensor (LAPS) have been extensively studied [4]. In the development of new drugs, there are many cases due to enzymatic reactions. Since LAPS measures charge density on the surface of the sensor, such as $\mathrm{pH}$, it is not suitable for measurement of small changes of substances caused by enzymes in environments close to a living cell. Therefore, we have been studied the light addressable amperometric sensor (LAAS) that enables two dimensional measurement of enzyme reaction by redox current. However, LAAS is suitable for concentration distribution measurement similarly to LAPS because it has the uniform surface without any wiring. Therefore, the purpose of this study is to fabricate the LAAS that measures multiple samples for drug screening. We tried to make LAAS capable of measuring multiple samples by attaching a well plate on the LAAS substrate. However, most of the wells were buried with adhesive. Therefore, we newly developed LAAS with planer structure well array using photolithography.

\section{METHODS}

\section{A. Fabrication of LAAS substrate}

Figure 1 shows the procedure for fabricating the LAAS substrate. An n-type silicon substrate of $2 \mathrm{~cm} \times 2 \mathrm{~cm}$ was cleaned with acetone for 10minutes and methanol for 10minutes, rinsed with distilled water, and then cleaned with fresh methanol for 10 minutes. The substrate was oxidized by putting it an oxidation furnace at a gas flow rate of $400 \mathrm{cc}$ and $1000^{\circ} \mathrm{C}$ for 90 minutes (Fig.1-1). In order to prevent photo resist from peeling off during etching, the substrate was treated with HDMS by spin coating at $700 \mathrm{rpm}$ for 30 seconds and baked at $110^{\circ} \mathrm{C}$ for 5minutes. Further we deposited positive photo resist (MICROPOSIT photo resist) by spin coating at the primary 
ISSN: 2277-3754

ISO 9001:2008 Certified

International Journal of Engineering and Innovative Technology (IJEIT)

Volume 10, Issue 8, February 2021

speed of 500rpm for 10seconds and the secondary speed of $3000 \mathrm{rpm}$ for 30 seconds and baked the film at $80^{\circ} \mathrm{C}$ for 20minutes. The photo resist film on the substrate was exposed through photomask A (Fig.1-2). After exposure, we developed the film and baked it at $120^{\circ} \mathrm{C}$ for 40 minutes using electric furnace (Fig.1-3). The substrate was immersed in hydrofluoric acid (HF 4.6\%) for 10 minutes to remove the exposed oxide layer (Fig.1-4). Thereafter, we deposited gold on the pan aluminum on the bottom with vacuum evaporation. The deposition area of aluminum was restricted to the fringe of substrate and the electrode functions as the common back contact electrode of the n-type silicon substrate (Fig.1-5). Finally, we removed the photo resist and the gold thereon with acetone (Fig.1-6) the separated gold electrodes function as the electrodes of Schottky junctions and individual working electrodes.

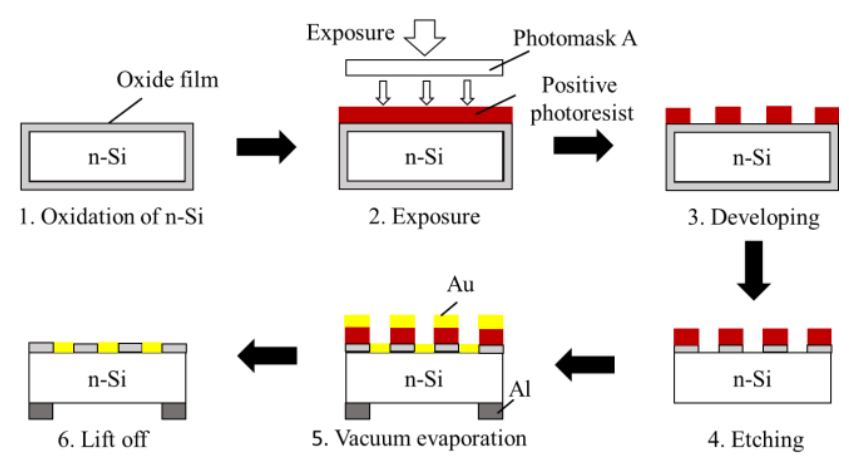

Fig. 1: Procedure of fabricating LAAS substrate

Figure 2 shows the photomask $A$ used in the photolithography of the LAAS substrate shown in figure 1. This is a universal printed circuit board, the diameter of the through-hole is $0.9 \mathrm{~mm}$ and the pitch is $2.54 \mathrm{~mm}$.

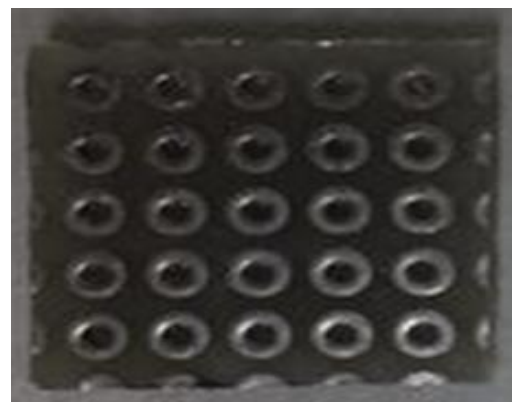

Fig. 2:The photomask A used in the photolithography of LAAS substrate

\section{B. Fabrication of well array}

Measurement of multiple samples become possible by forming wells on the LAAS substrate. We used SU-8, a negative photo resist because SU-8 is frequently used in microstructure and has high durability [5]. Figure 3 shows the procedure of well array fabrication on LAAS substrate. We spin-coated SU-8 (SU-8 2000 series, MIKROCHEM) on LAAS substrate at the primary speed of $500 \mathrm{rpm}$ for 10 seconds and the secondary speed of $2000 \mathrm{rpm}$ for 30 seconds (Fig.3-1). The LAAS substrate was baked at $60^{\circ} \mathrm{C}$ for 8 minutes and $90^{\circ} \mathrm{C}$ for 40 minutes and exposed through a photo mask B for 12 minutes (Fig.3-2). After exposure, the SU-8 film was baked at $60^{\circ} \mathrm{C}$ for 7 minutes and $90^{\circ}$ for 20 minutes, and deposited platinum with sputtering for 35 seconds (Fig.3-3). Then, we developed the LAAS for 40 minutes and baked at $120^{\circ} \mathrm{C}$ for 20 minutes (Fig.3-4).

We further deposited SU-8 on the platinum in order to equalize contact area between platinum and the solution. We spin-coated SU-8 on this LAAS substrate at primary speed of $500 \mathrm{rpm}$ for 10 seconds and the secondary speed of $2000 \mathrm{rpm}$ for 30 seconds and baked the substrate at $60^{\circ} \mathrm{C}$ for 45 minutes (Fig.3-5). After baking, we exposed the substrate for 12 minutes through photo mask B and baked the substrate again at $60^{\circ} \mathrm{C}$ for 7 minutes and at $90^{\circ} \mathrm{C}$ for 20 minutes (Fig3-6). Finally, we developed this substrate and baked it in an electric furnace at $120^{\circ} \mathrm{C}$ for 20 minutes (Fig.3-7). SU-8 functions as an insulating film and platinum functions as a common counter electrode.

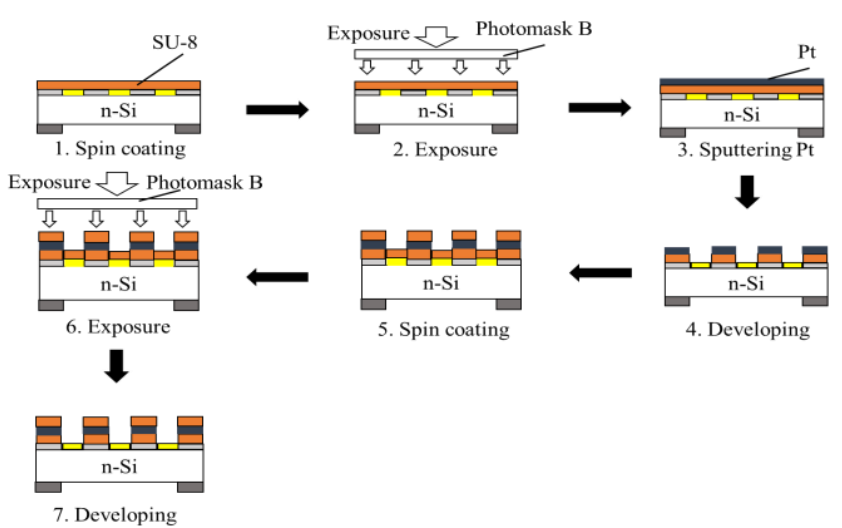

Fig. 3: Procedure of well array fabrication on LAAS substrate 
ISSN: 2277-3754

ISO 9001:2008 Certified

\section{International Journal of Engineering and Innovative Technology (IJEIT)}

Volume 10, Issue 8, February 2021

Figure 4 shows the photomask $\mathrm{B}$ used in the photolithography of the well array shown in figure 3 . The diameter of circle is about $0.9 \mathrm{~mm}$ and the pitch is 2.54 $\mathrm{mm}$.

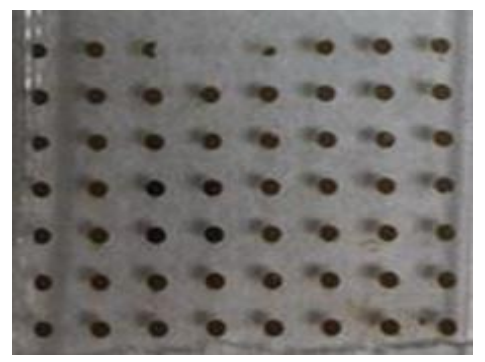

Fig. 4: The photomask B used in the photolithography of the well array

We created this photomask $\mathrm{B}$ with a universal printed circuit board. Figure 5 shows the procedure for manufacturing photomask B. A glass plate with size of 3 $\mathrm{cm} \times 3 \mathrm{cmwas}$ ultrasonicated with acetone for 10 minutes, methanole for 10 minutes, distilled water for 10 minutes, methanol for 10 minutes, finally for distilled water for 10 minutes. After cleanig, we spin-coated the positive photoresist on the glass plate at the primary speed of 500 rpm for 10 seconds and the secondary speed of $3000 \mathrm{rpm}$ for 30 seconds (Fig.5-1). After baking at $80^{\circ} \mathrm{C}$ for 20 minutes in an electric furnace, we exposed the glass plate for 60 seconds using the universal printed circuit board as a photomask (Fig.5-2). After exposure, we developed the photoresist (Fig.5-3)and then deposited titanium over it for 5 minutes (Fig.5-4) and platinum thereon for 5 minutes with sputtering (Fig.5-5). After deposition, we completed the lift off of the photoresistand metals with acetone (Fig.5-6).

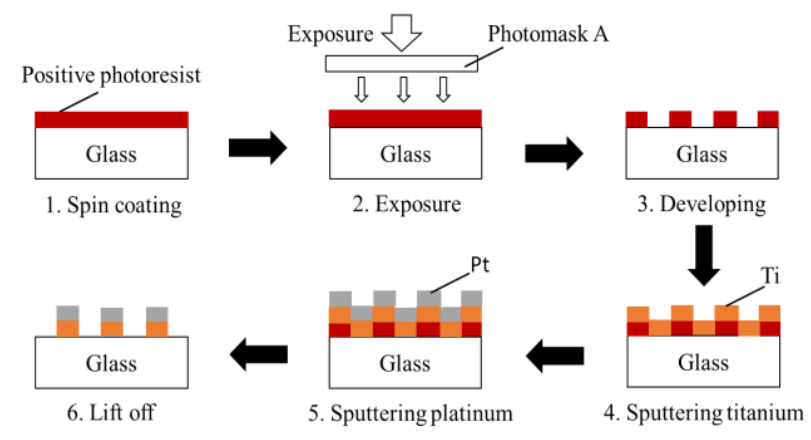

Fig. 5: Procedure for manufacturing photomask

\section{Measurement of mediator}

In this study, we measured redox current with a solution containing mediator and supporting salt. The oxidant was potassium ferricyanide $\mathrm{K}_{3}\left[\mathrm{Fe}(\mathrm{CN})_{6}\right]$ and the reluctant was potassium ferrocyanide $\mathrm{K}_{4}\left[\mathrm{Fe}(\mathrm{CN})_{6}\right]$. We measured the current with varying concentration from $1 \mathrm{pM}$ to $1 \mathrm{mM}$ of redox species. Support salt was $0.1 \mathrm{M}$ sodium sulfate $\mathrm{Na}_{2} \mathrm{SO}_{4}$, and averaged the last 3 out of 4 measurements.

We dropped $1.2 \mu \mathrm{l}$ of solution into each of 4 wells on LAAS. Figure 6 shows the principle of single well measurement by LAAS. The equilibrium state of redox reaction is broken by photovoltaics of Schottky junction by irradiating light beam from the backside of the well. The observed current depends on the concentration of redox species in the well.

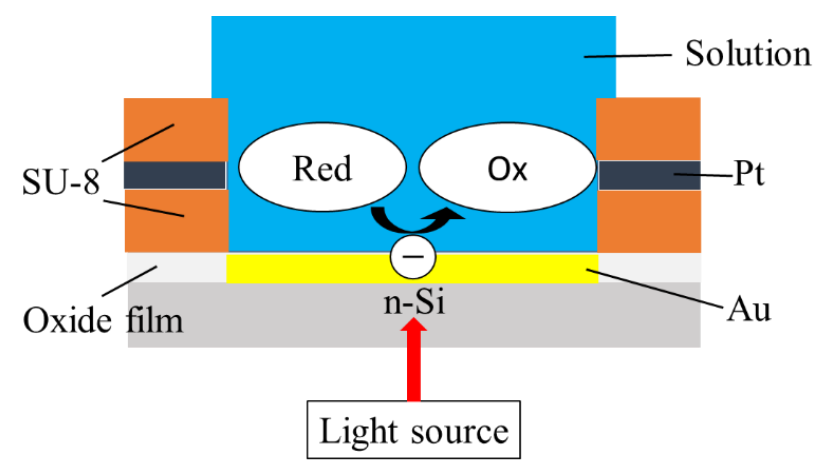

Fig. 6: Principle of LAAS

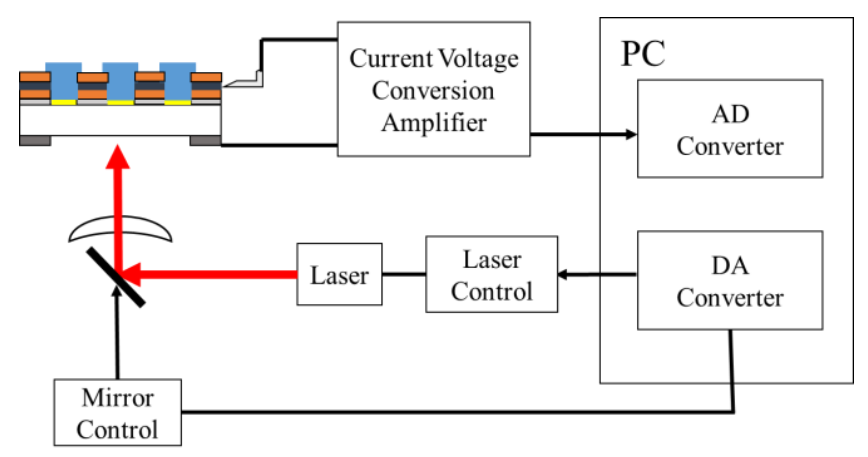

Fig. 7: Schematic of the LAAS measurement system

Figure 7 shows the measurement system of LAAS. The LAAS performs individual measurements by selecting each well using addressing light. We controlled the intensity of the excitation laser and the angle of the mirror with the PC. We amplified the current output from LAAS with a current 
ISSN: 2277-3754

\section{ISO 9001:2008 Certified}

International Journal of Engineering and Innovative Technology (IJEIT)

Volume 10, Issue 8, February 2021

voltage conversion amplifier (FEMTO messtechnik DDPCA-300) and sampled with AD converter. Moreover, we performed two dimensional measurement of redox current on LAAS with a scanning laser. Irradiating a focused laser of 30 points vertically with 30 points horizontally acquire a two dimensional image of $8.5 \mathrm{~mm} \times$ $8.5 \mathrm{~mm}$ area. We used an infrared laser source (THORLABS S1FC980) with a wave length of $980 \mathrm{~nm}$ and output of $15 \mathrm{~mW}$.

\section{Evaluation of redox current}

Methods of voltammetry to evaluate redox current are various, and the differential pulse voltammetry (DPV) is one of methods that possess high detection sensitivity [6]. We analyzed redox current of LAAS based on the technique similar to DPV by switching the excitation laser to modulate the interface potential between the gold electrode and the solution. Figure 8 shows the evaluation method of redox current. The excitation light flashed during a half period of $120 \mathrm{~ms}$. The observed current is sum of the charge current of the electric double layer and the redox current. Therefore, we used the value of difference between $\mathrm{ON}$ and OFF periods as the redox current. The value of each period is obtained by averaging the wave in the last 20 $\mathrm{ms}$ of the period in order to avoid influence of the charging current.

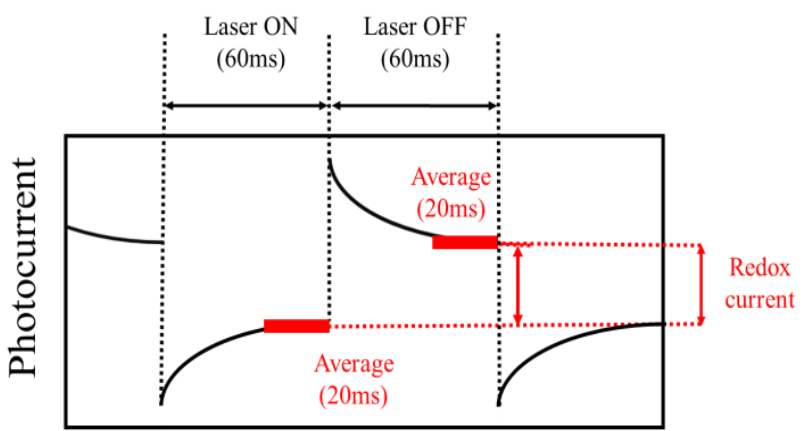

Time

Fig. 8: Evaluation of redox current

\section{RESULTS}

\section{A. Redox current measurement}

Figure 9a shows the top view of the fabricated LAAS device. The size of the LAAS substrate is $2 \mathrm{~cm} \times 2 \mathrm{~cm}$. The proposed method patterns $7 \times 7$ wells. However, we found that some wells did not be patterned correctly. Figure $9 b$ shows a two dimensional image of $30 \times 30$ measurement points obtained by redox current measurement with scanning laser in the domain that is surrounded in a dotted line shown in Fig. 9a. We dropped a solution containing $1 \mathrm{mM} \mathrm{K}_{3}\left[\mathrm{Fe}(\mathrm{CN})_{6}\right]$ and $\mathrm{K}_{4}\left[\mathrm{Fe}(\mathrm{CN})_{6}\right]$ into four wells around the center of the LAAS and measured redox current map. The current values of the wells holding the solution are clearly larger than that of empty wells.

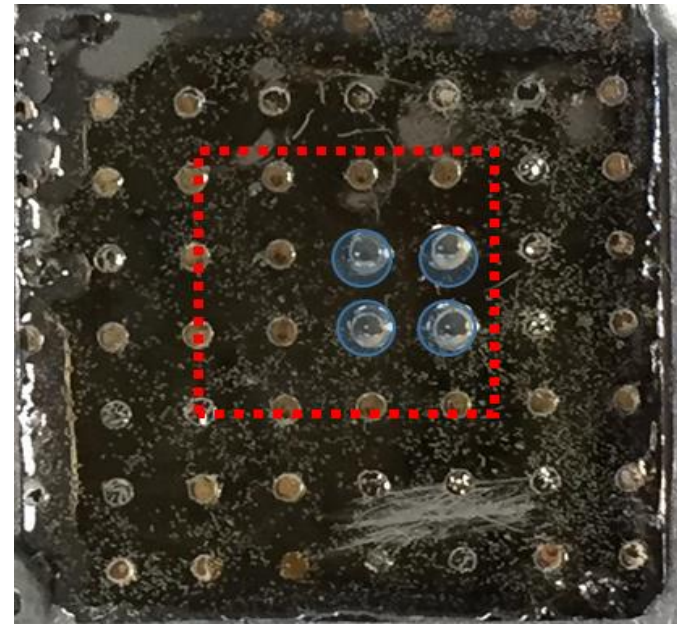

(a) LAAS device

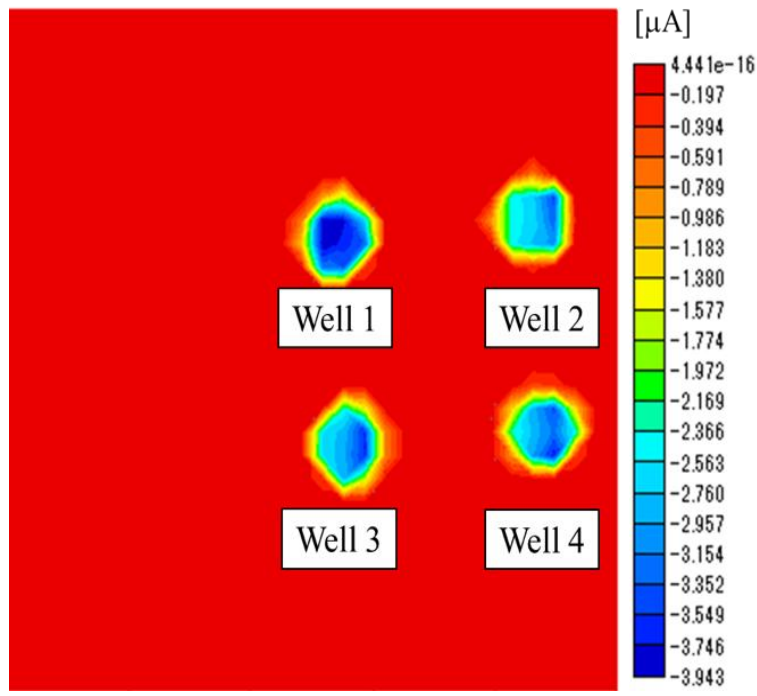

(b) Two dimensional image of redox current

Fig. 9: Image of redox current of LAAS device with four samples in wells 1-4 
ISSN: 2277-3754

ISO 9001:2008 Certified

International Journal of Engineering and Innovative Technology (IJEIT)

Volume 10, Issue 8, February 2021

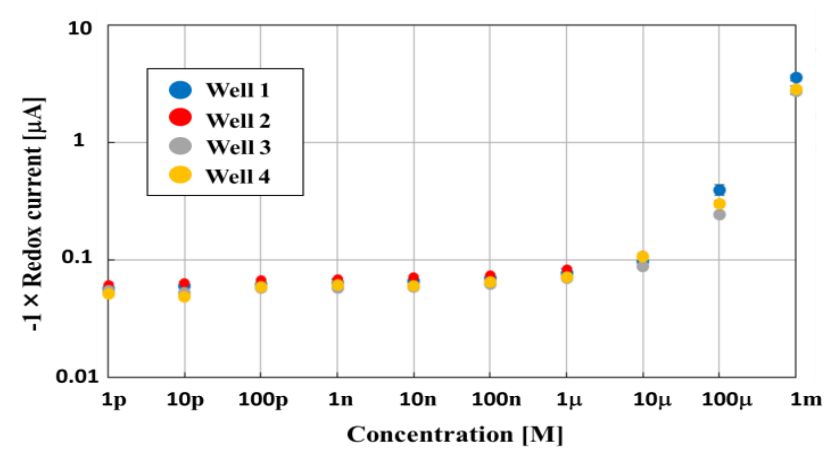

Fig. 10: Solution concentration characteristics

Figure 10 shows the concentration dependency of the redox current of LAAS. Although the each curve contains two different straight lines changing at around $1 \mathrm{uM}$, the redox current monotonically decreases relative to the concentration of the redox species. Moreover, we observed the redox current in all wells from $100 \mathrm{nM}$ to $1 \mathrm{mM}$.

Table 1 shows the absolute value of average, Relative value based on $1 \mathrm{pM}$, standard deviation, and signal to noise ratio ( $\mathrm{SN}$ ratio) depending on concentration for each well. We observed the variation in the value of $\mathrm{SN}$ ratio for each well.

Table 1: The value of $\mathrm{SN}$ ratio depending on concentration for each well

\begin{tabular}{|c|c|c|c|c|c|}
\hline & Concentration $[\mathrm{M}]$ & $\begin{array}{c}\text { Ia } \\
\text { (Absolute value of average) } \\
{[\mathrm{A}]}\end{array}$ & $\begin{array}{c}\text { Is } \\
\text { (Relative value based on } 1 \mathrm{pM} \text { ) } \\
{[\mathrm{A}]}\end{array}$ & $\begin{array}{c}\text { In } \\
\text { (Standard deviation ofIa) }\end{array}$ & $\mathrm{SN}$ ratio(Is/In) \\
\hline \multirow{10}{*}{ Well1 } & $1 \mathrm{~m}$ & 3.6 & 3.5 & 0.19 & 18.1 \\
\hline & $100 \mathrm{u}$ & 0.40 & 0.34 & 0.041 & 8.4 \\
\hline & $10 \mathrm{u}$ & 0.098 & 0.040 & 0.0036 & 11.1 \\
\hline & $1 \mathrm{u}$ & 0.0772 & 0.0198 & 0.00096 & 20.8 \\
\hline & $100 \mathrm{n}$ & 0.070 & 0.013 & 0.0012 & 11.2 \\
\hline & $10 \mathrm{n}$ & 0.0668 & 0.0094 & 0.00032 & 29.6 \\
\hline & $1 \mathrm{n}$ & 0.0641 & 0.0067 & 0.00045 & 14.9 \\
\hline & $100 p$ & 0.0622 & 0.0048 & 0.00062 & 7.8 \\
\hline & $10 p$ & 0.060 & 0.003 & 0.0013 & 2.2 \\
\hline & $1 p$ & 0.057 & 0 & 0.0019 & 0 \\
\hline \multirow{10}{*}{ Well2 } & $1 \mathrm{~m}$ & 2.8 & 2.76 & 0.26 & 10.7 \\
\hline & $100 \mathrm{u}$ & 0.31 & 0.24 & 0.021 & 11.5 \\
\hline & $10 \mathrm{u}$ & 0.111 & 0.049 & 0.0034 & 14.1 \\
\hline & $1 \mathrm{u}$ & 0.0846 & 0.0224 & 0.00038 & 58.6 \\
\hline & $100 \mathrm{n}$ & 0.0749 & 0.0127 & 0.00062 & 20.6 \\
\hline & $10 \mathrm{n}$ & 0.0715 & 0.0093 & 0.00034 & 27.3 \\
\hline & $1 \mathrm{n}$ & 0.0696 & 0.0073 & 0.00049 & 14.8 \\
\hline & $100 p$ & 0.0683 & 0.0060 & 0.00047 & 12.9 \\
\hline & $10 \mathrm{p}$ & 0.064 & 0.002 & 0.0016 & 1.4 \\
\hline & $1 p$ & 0.062 & 0 & 0.0029 & 0 \\
\hline \multirow{10}{*}{ Well3 } & $1 \mathrm{~m}$ & 2.8 & 2.7 & 0.35 & 7.8 \\
\hline & $100 \mathrm{u}$ & 0.25 & 0.19 & 0.019 & 10.4 \\
\hline & $10 \mathrm{u}$ & 0.088 & 0.033 & 0.0021 & 15.6 \\
\hline & $1 \mathrm{u}$ & 0.0706 & 0.0157 & 0.00068 & 23.2 \\
\hline & $100 n$ & 0.0626 & 0.008 & 0.00089 & 8.6 \\
\hline & $10 \mathrm{n}$ & 0.0599 & 0.0050 & 0.00027 & 18.3 \\
\hline & $1 \mathrm{n}$ & 0.0588 & 0.0038 & 0.00030 & 13.0 \\
\hline & $100 p$ & 0.0580 & 0.0031 & 0.00052 & 5.9 \\
\hline & $10 p$ & 0.0533 & -0.0017 & 0.00065 & -2.6 \\
\hline & $1 p$ & 0.055 & 0 & 0.0014 & 0 \\
\hline
\end{tabular}


ISSN: 2277-3754

ISO 9001:2008 Certified

International Journal of Engineering and Innovative Technology (IJEIT)

Volume 10, Issue 8, February 2021

\begin{tabular}{|c|c|c|c|c|c|}
\hline \\
\hline \multirow{10}{*}{ Well4 } & $1 \mathrm{~m}$ & 2.9 & 2.8 & 0.34 & 8.3 \\
\hline & $100 \mathrm{u}$ & 0.31 & 0.25 & 0.019 & 13.3 \\
\hline & $10 \mathrm{u}$ & 0.108 & 0.056 & 0.0039 & 14.5 \\
\hline & $1 \mathrm{u}$ & 0.071 & 0.020 & 0.0010 & 19.5 \\
\hline & $100 \mathrm{n}$ & 0.066 & 0.014 & 0.0010 & 13.2 \\
\hline & $10 \mathrm{n}$ & 0.0610 & 0.0091 & 0.00068 & 13.4 \\
\hline & $1 \mathrm{n}$ & 0.0612 & 0.0094 & 0.00064 & 14.6 \\
\hline & $100 p$ & 0.0593 & 0.0074 & 0.00059 & 12.6 \\
\hline & $10 \mathrm{p}$ & 0.049 & -0.003 & 0.0010 & -2.6 \\
\hline & $1 \mathrm{p}$ & 0.052 & 0 & 0.0017 & 0 \\
\hline
\end{tabular}

Table 2 shows the minimum concentration of detection limit of each well. We defined the detection limit as the lowest concentration that signal to noise ratio becomes more than two and backward difference keeps positive. We observed the variation in the value of detection limit for each well.

Table 2:The minimum concentration of detection limit for

\begin{tabular}{|c|c|c|}
\multicolumn{2}{c}{} & each well \\
\hline \multirow{3}{*}{} & $\begin{array}{c}\text { The minimum concentration of } \\
\text { detection limit }(M)\end{array}$ \\
\hline \multirow{4}{*}{ Well } & 1 & $10 \mathrm{p}$ \\
\cline { 2 - 3 } & 2 & $100 \mathrm{p}$ \\
\cline { 2 - 3 } & 3 & $100 \mathrm{p}$ \\
\cline { 2 - 3 } & 4 & $100 \mathrm{n}$ \\
\hline
\end{tabular}

Figure 11 is an enlarged view of the concentration characteristic of the well 1 in the low concentration region. The vertical bar for each mark in the figure is the standard deviation of 3 times measurement. From this result we observed concentration dependence from $10 \mathrm{pM}$ to $1 \mathrm{mM}$ using well 1.

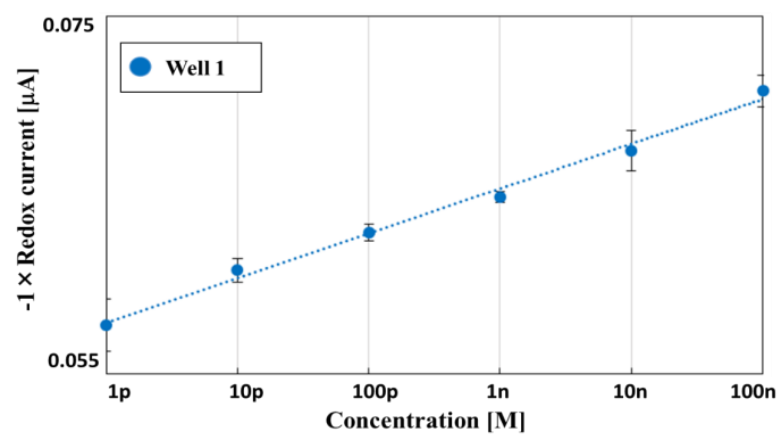

Fig. 11: Solution concentration characteristics of well 1

\section{B. Discussion}

We found that some wells did not be patterned correctly on the LAAS substrate. Possible reason for this failure is that we could not lift off platinum because the film thickness of platinum is large. We deposited platinum using sputtering. Therefore, we are able to thin the film thickness by shortening the sputtering time. It can be considered that the thinner metal film will be easily lifted off and more wells will be patterned correctly. However, we found that the proposed structure of LAAS functioned correctly based on the result of two dimensional imaging of redox current.

We have concluded that the difference in the minimum concentration of detection limit per well may have been caused by the difference in platinum area per well due to erosion of SU-8 to platinum. Reducing the well size of the photo mask prevents corrosion of SU-8, and we can reduce the variability. We observed two straight lines with different in double logarithmic chart. The straight line in the lower concentration region seems to be a dependency based on the limited current due to the ion diffusion and transportation because of few ions in the solution. On the other hand, the straight line in the higher concentration region seems to be a pure concentration dependent because the density of ions in the solution are sufficiently large compared to the amount of excited charge in LAAS.

\section{Conclusion}

In this study, we fabricated the LAAS that enables multiple samples measurement and we successfully measured extremely low concentration of redox species. From this result we expect cost reduction of the measurement such as drug screening of enzyme inhibitors. We will approach to an application of drug screening using not only solution of mediator but also solution containing 
ISSN: 2277-3754

ISO 9001:2008 Certified

International Journal of Engineering and Innovative Technology (IJEIT)

Volume 10, Issue 8, February 2021

enzyme and substrate.

\section{REFERENCES}

[1] Mohammad A. Azad, Juan G. Osorio, David Brancazio, Gregory Hammersmith, David M. Klee,Kersten Rapp, Allan Myerson, "A compact, portable, re-configurable, and automated system for on-demand pharmaceutical tablet manufacturing", International Journal of Pharmaceutics, Vol.539, PP:157-164, 2018.

[2] Arsia Amir-Aslani, Vincent Mangematin, "The future of drug discovery and development: Shifting emphasis towards personalized medicine", Technological Forecasting and Social Change, Vol. 77, PP: 203-217, 2010.

[3] Rebecca N. Adamek, Roxanne V. Maniquis, SabahaKhakoo, Michael D. Bridges, Nicholas T. Salzameda, "A FRET-based assay for the discovery of West Nile Virus NS2B-NS3 protease inhibitors", Bioorganic \& Medicinal Chemistry Letters, Vol. 23, PP: 4848-4850, 2013.

[4] Jian Wang, Liping Du, Steffi Krause, Chunsheng Wu, Ping Wang, "Surface modification and construction of LAPS towards biosensing applications", Sensors and Actuators B: Chemical, Vol. 265, PP:161-173, 2018.

[5] Gonzalo Murillo, Zachary J. Davis, Stephan Keller, Gabriel Abadal, Jordi Agusti, Alberto Cagliani, Nadine Noeth, Anja Boisen, NuriaBarniol, "Novel SU-8 based vacuum wafer-level packaging for MEMS devices", Microelectronic Engineering, Vol. 87, Issue 5-8, May-August, PP:1173-1176 2010.

[6] Yuanyuan Lu, Xinqiang Liang, Christophe Niyungeko, Junjie Zhou, Jianming Xu, Guangming Tian, "A review of the identification and detection of heavy metal ions in the environment by voltammetry”, Talanta, Vol. 178, 1 February 2018, PP: 324-338, 2018. 